\title{
Experimental Study of Electric and Spectroscopic Characteristics of Electric Discharge in LPG
}

\author{
Ahmed Abd Elradi' ${ }^{1}$ Nasser N. Morgan ${ }^{1,2}$, Sobhy Ghalab ${ }^{1,2}$, Mansour Elsabagh ${ }^{1,2}$, \\ Safwat Hassaballa ${ }^{1,2}$, Ahmed Samir ${ }^{1 *}$, Farouk F. Elakshar1, ${ }^{1,2}$, Abdou A. Garamoon ${ }^{1,2}$ \\ ${ }^{1}$ Center of Plasma Technology, Al Azhar University, Cairo, Egypt \\ ${ }^{2}$ Physics Department, Faculty of Science, Al-Azhar University, Cairo, Egypt \\ Email: ${ }^{\text {ahmed samir aly@yahoo.com }}$
}

Received 23 July 2014; revised 21 August 2014; accepted 5 September 2014

Copyright (C) 2014 by authors and Scientific Research Publishing Inc.

This work is licensed under the Creative Commons Attribution International License (CC BY). http://creativecommons.org/licenses/by/4.0/

(c) (i) Open Access

\section{Abstract}

Electric discharge has been carried out in LPG using DC high voltage (0.4 - $3 \mathrm{KV})$ at gas pressure in the range of 1 to 25 torr. The electric and spectroscopic characteristics of the discharge were studied at different discharge conditions. Deviations from Paschen's law were observed as a result of the change of the distance between the two the electrodes. Two discharge modes, namely glow discharge and spark discharge modes, has been observed in the discharge current waveforms. The discharge current waveforms indicate a repetitive pulsed behaviour with frequencies of $5 \mathrm{kHz}$ to 5 MHz depending upon the applied voltage and the gas pressure. The emitted spectra from the discharge are also studied near both the cathode and the anode using different electrode materials. $H_{\alpha}$ line and C2 Swan band system are observed, which confirms the conversion of LPG to hydrogen and carbon clusters.

\section{Keywords}

Liquefied Petroleum Gas, Electric Discharge, Hydrogen Production, Propane Decomposition, Butane Decomposition

\section{Introduction}

Liquefied petroleum gas (LPG) is a mixture of hydrocarbon-based gases, mainly propane and butane gases. Natural gas purification produces about 55 percent of all LPG, while crude oil refining produces about 45 per-

\footnotetext{
${ }^{*}$ Corresponding author.
} 
cent. LPG is widely used as a household fuel for heating and cooking in many countries. Its transportability and easy storage have boosted its popularity. LPG is rarely used as a vehicles fuel although it generates lower air pollutants than gasoline [1] even though lower energy output, (about $74 \%$ of the gasoline energy output) is expected [2]. The low energy output of LPG reduces the interest of using it as a common alternative fuel for vehicles. To overcome the low energy output some reforming of LPG is required.

Recently electric discharge has been widely used for reforming the hydrocarbon gases. Although there are some publications in the literature for using the electric discharge for the conversion of methane, ethane, acetylene and other hydrocarbons to hydrogen [3]-[6], there is shortage in the investigations of the conversion of LPG to hydrogen using the electric discharge technique in the literatures. The electric discharge is expected to be an efficient technique for conversion of LPG to other alternative fuel gases such as hydrogen. Investigation of the electric and spectroscopic characteristics of the electric discharge in LPG is one of the important keys to understand the conversion mechanisms and achieve efficient reforming of LPG.

The aim of the present work is to explore the discharge mechanism in LPG by studying the electric and spectroscopic characteristics of the discharge.

\section{Experimental Setup}

Figure 1(a) shows a schematic diagram of the experimental setup of the electric discharge system. Figure 1(b)

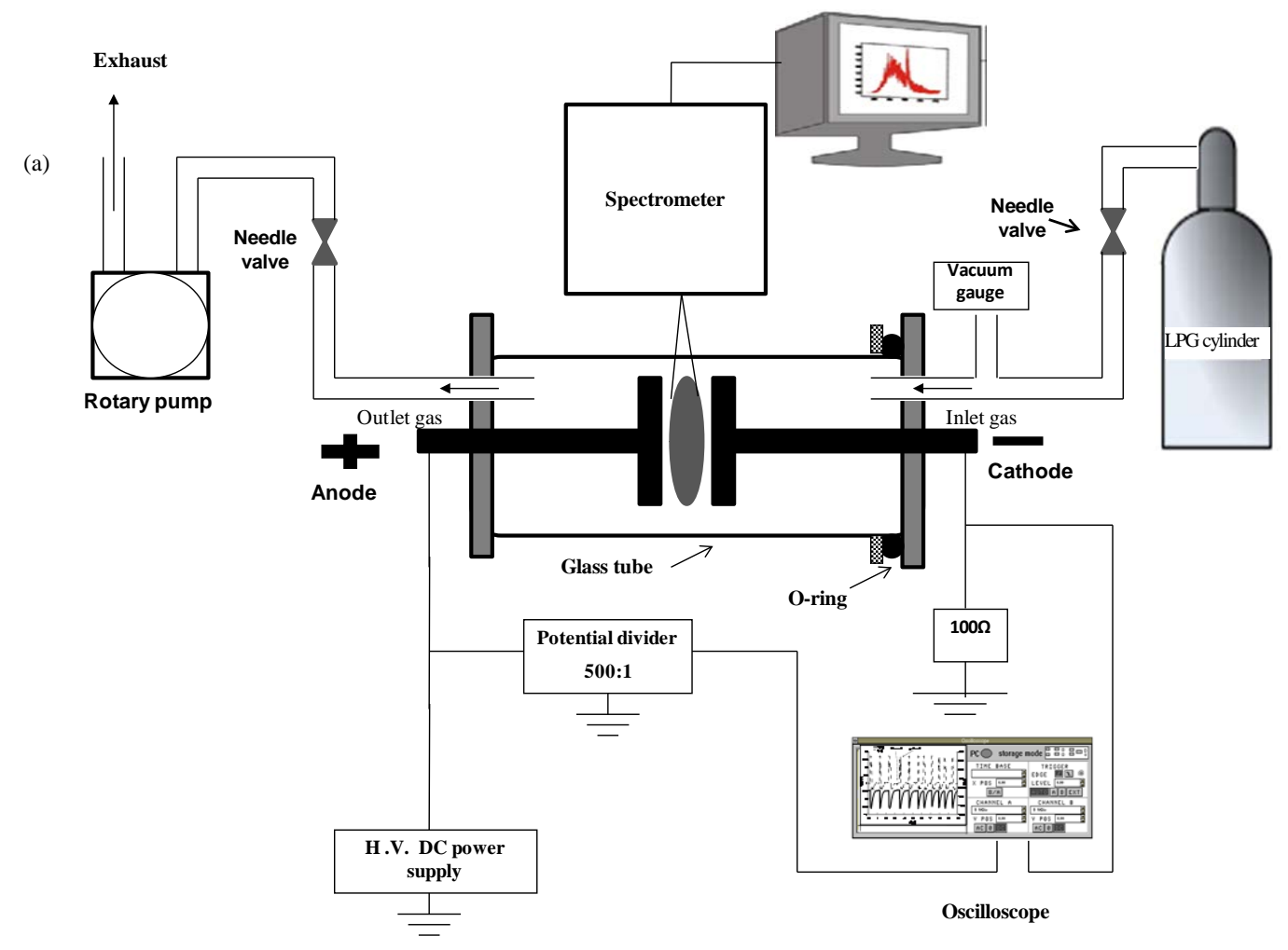

(b)

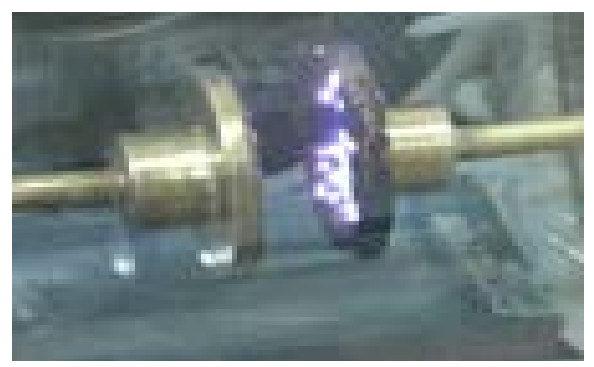

Figure 1. (a) Schematic diagram of the experimental arrangements; (b) photographic plate of the LPG discharge. 
shows a photographic plate of the discharge in LPG. The discharge cell consists of a cylindrical glass vessel with $80 \mathrm{~mm}$ diameter and $110 \mathrm{~mm}$ length. Two movable electrodes have been placed on the axe of the glass tube. The electrodes are made of brass (alloy of copper and zinc) and they are coated with nickel in some measurements. The electrode diameter is $30 \mathrm{~mm}$, and the gap distance between the two electrodes is varied from 1 to 10 $\mathrm{mm}$. The vessel has been evacuated to base pressure of $10^{-2}$ torr using rotary pump and then the LPG has been left to flow through the discharge cell at constant flow rate of $1 \mathrm{~L} / \mathrm{min}$. The used samples of LPG consist of about $65 \%$ butane $\left(\mathrm{C}_{4} \mathrm{H}_{10}\right)$ and $35 \%$ propane $\left(\mathrm{C}_{3} \mathrm{H}_{8}\right)$. Some traces of other hydrocarbons such as ethane, ethylene, propylene, butylene, etc are also expected. Using two needle valves, before and after the vessel, the LPG pressure in the vessel has been controlled in the range of 1 - 25 torr. A DC power supply $(0-3 \mathrm{kV})$ has been used as high voltage source. A resistance of $22 \mathrm{k} \Omega$ has been used to limit the discharge current. The discharge voltage has been measured via a potential divider (500:1) while the discharge current has been measured by measuring the potential drop across a resistance of $100 \Omega$. The voltage and current waveforms have been recorded using digital storage oscilloscope (type HM1508). A spectrometer (Type: Solar laser systems M266) has been used for the spectroscopic measurements. The slit width of the spectrometer has been adjusted to be 50 microns.

\section{Results and Discussion}

\subsection{Electric Characteristics}

The breakdown voltage $\left(\mathrm{V}_{\mathrm{b}}\right)$ of LPG has been measured at different values of gas pressures and distances between the two electrodes. Figure 2 shows the Paschen's curve at a distance of $1 \mathrm{~mm}$ between the two electrodes and different values of the gas pressure i.e. different pd. The minimum breakdown voltage $\left(\mathrm{V}_{\mathrm{bmin}}\right)$ has been found to be $0.47 \mathrm{kV}$ at pd value of 0.42 torr.cm $\left(\mathrm{pd}_{\min }\right)$. Figure 3 shows the Paschen's curves at different distances between the two electrodes. A deviation from Paschen's curves has been noticed as shown in Figure 3, where the values of $V_{b}$ at the same Pd do not coincide. Higher breakdown voltages have been obtained at longer distances between the two electrodes and at the same values of pd. A similar deviation has been reported in the literatures for the inert gases (e.g. helium, neon, argon, krypton, and xenon) [7]-[9]. No deviations from Paschen's law for hydrocarbon gases were reported in the literatures. The deviation from Paschen's law occurs when the active secondary ionization processes at the electrodes surface or in the discharge volume are due to the photons and/or the excited atoms or molecules [8]. This confirms the importance role of the photons and/or the excited atoms and/or molecules as a secondary ionization processes in the electric breakdown of LPG in the present discharge conditions.

Figure 4 shows the discharge voltage and the discharge current waveforms in LPG at a gas pressure of 20 torr and $3 \mathrm{~mm}$ distance between the two electrodes. Two different components of the discharge current are observed in Figure 4, a glow discharge mode and a spark discharge mode. The glow discharge component mode is characterized by a uniform current of low values in the order of few tens of $\mathrm{mA}$, while the spark discharge component is characterized by high current component in the order of hundreds of $\mathrm{mA}$ with a pulsed behaviour of a very short time (around $50 \mathrm{~ns}$ ). The photographic plate in Figure 1(b) indicates that the discharge in LPG is very bright discharge channels that are rotating upon the electrode surface. The spark channels play an important role in the conversion processes of the hydrocarbons to hydrogen.

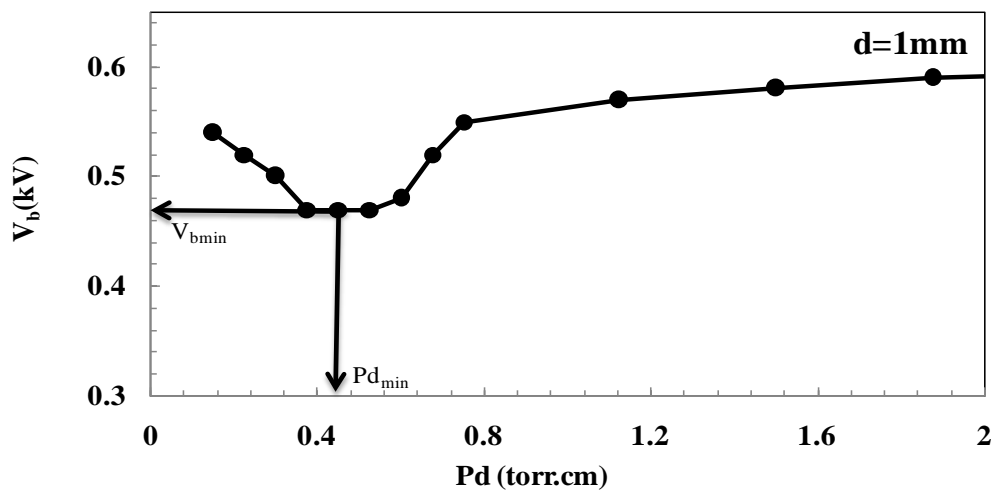

Figure 2. Paschen's curve at $1 \mathrm{~mm}$ distance between the two electrodes. 


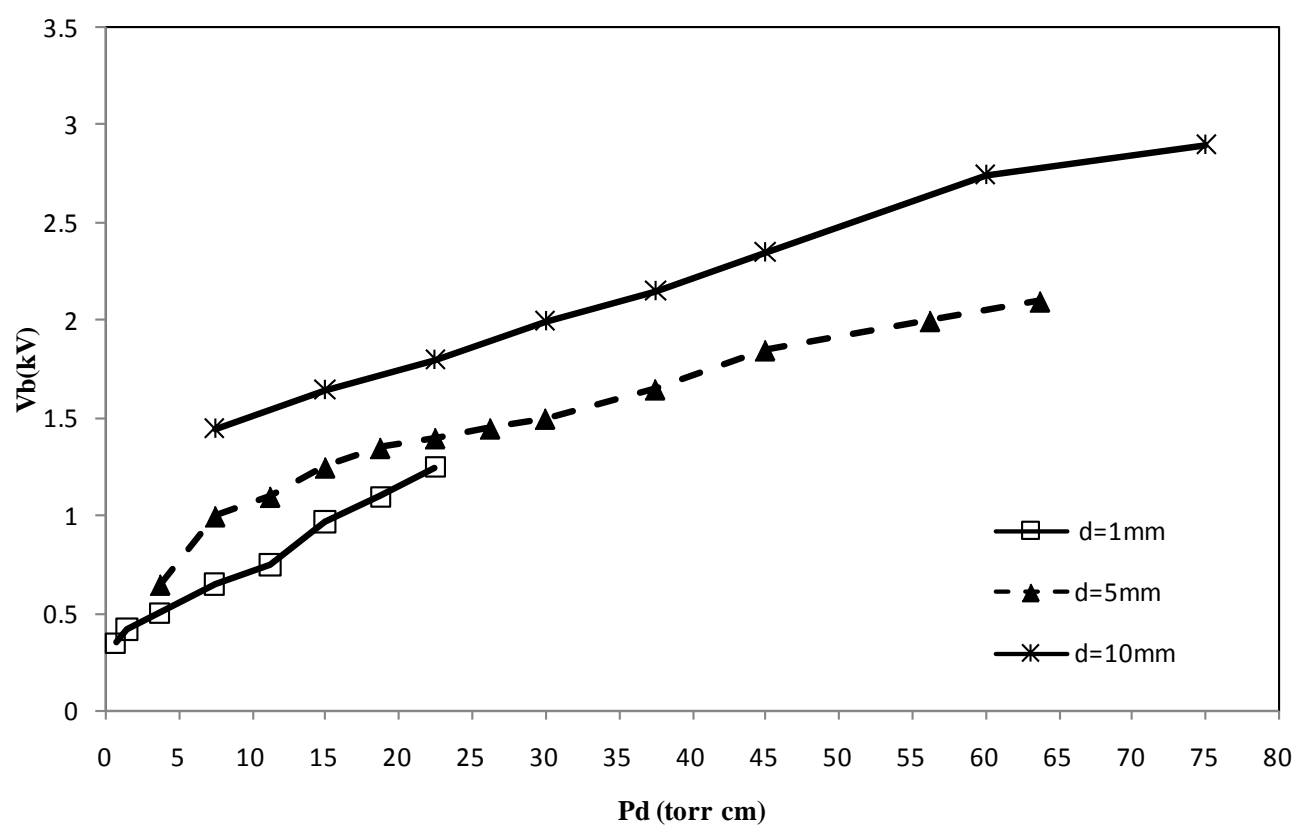

Figure 3. Paschen's curves at different distances between the two electrodes.

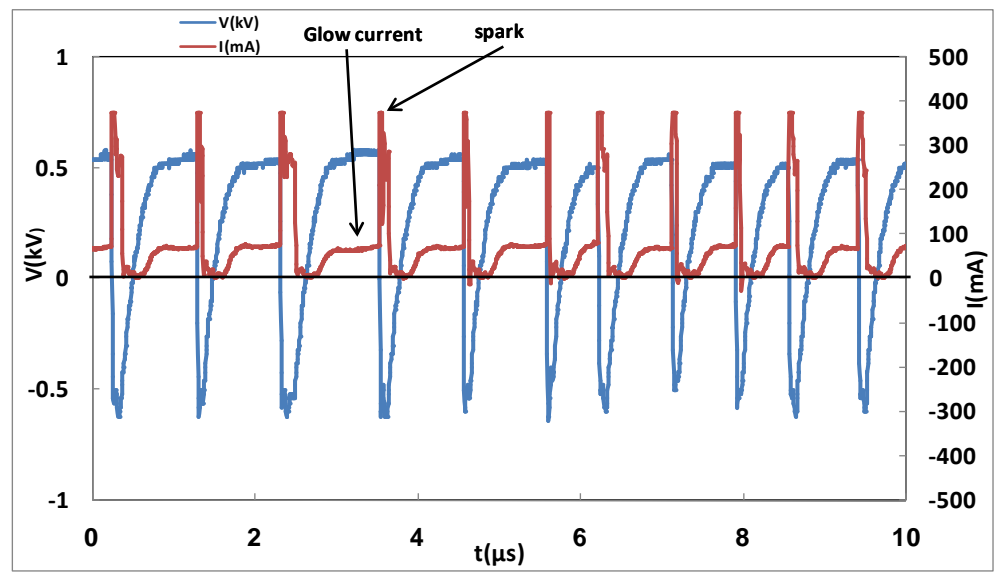

Figure 4. Voltage and current waveforms.

The transition from glow to spark discharge modes can be explained as follows: as the glow discharge mode is formed some of propane and butane molecules are decomposed forming hydrogen atoms and different carbon species. The hydrogen atoms play an important role in increasing the ionization processes in the gas and hence transforming the discharge mode to spark mode and subsequently increases the current very sharply to very high value [10] [11]. The enhancement of discharge current as a subsequent increase in the produced $\mathrm{H}$ atoms is related to the increase of the ionization processes through:

Ionization of $\mathrm{H}$ atoms and through the following processes:

1) The secondary ionization process produced by the hydrogen metastable state $H^{*}$ which has a relatively long lifetime up to $012 \mathrm{sec}$ [11]. According to the following reactions [11]-[15]:

$$
\begin{aligned}
& \mathrm{C}_{3} \mathrm{H}_{8}+\mathrm{e} \rightarrow \mathrm{C}_{2} \mathrm{H}_{4}+\mathrm{CH}_{4}+\mathrm{e} \\
& \mathrm{C}_{3} \mathrm{H}_{8}+\mathrm{e} \rightarrow \mathrm{C}_{3} \mathrm{H}_{6}+\mathrm{H}_{2}+\mathrm{e} \\
& \mathrm{C}_{3} \mathrm{H}_{6}+\mathrm{e} \rightarrow \mathrm{C}_{2} \mathrm{H}_{2}+\mathrm{CH}_{4}+\mathrm{e} \\
& \mathrm{C}_{2} \mathrm{H}_{4}+\mathrm{e} \rightarrow \mathrm{C}_{2} \mathrm{H}_{2}+\mathrm{H}_{2}+\mathrm{e}
\end{aligned}
$$




$$
\begin{aligned}
& 2 \mathrm{CH}_{4}+\mathrm{e} \rightarrow \mathrm{C}_{2}+4 \mathrm{H}_{2}+\mathrm{e} \\
& 2 \mathrm{C}_{4} \mathrm{H}_{10}+\mathrm{e} \rightarrow \mathrm{C}_{2}+2 \mathrm{C}_{3} \mathrm{H}_{8}+2 \mathrm{H}_{2}+\mathrm{e} \\
& \mathrm{C}_{3} \mathrm{H}_{8}+\mathrm{e} \rightarrow \mathrm{C}_{2} \mathrm{H}_{4}+\mathrm{CH}_{4}+\mathrm{e} \\
& \mathrm{C}_{3} \mathrm{H}_{8}+\mathrm{e} \rightarrow \mathrm{C}_{3} \mathrm{H}_{6}+\mathrm{H}_{2}+\mathrm{e} \\
& \mathrm{C}_{3} \mathrm{H}_{6}+\mathrm{e} \rightarrow \mathrm{C}_{2} \mathrm{H}_{2}+\mathrm{CH}_{4}+\mathrm{e} \\
& \mathrm{C}_{2} \mathrm{H}_{4}+\mathrm{e} \rightarrow \mathrm{C}_{2} \mathrm{H}_{2}+\mathrm{H}_{2}+\mathrm{e} \\
& 2 \mathrm{CH}_{4}+\mathrm{e} \rightarrow \mathrm{C}_{2}+4 \mathrm{H}_{2}+\mathrm{e} \\
& \mathrm{H}_{2}+\mathrm{e}(4.477 \mathrm{ev}) \rightarrow \mathrm{H}+\mathrm{H}+\mathrm{e} \\
& \mathrm{H}+\mathrm{e}(13.6 \mathrm{ev}) \rightarrow \mathrm{H}^{+}+\mathrm{e}+\mathrm{e} \\
& \mathrm{H}+\mathrm{e}(10.2 \mathrm{ev}) \rightarrow \mathrm{H}^{*}+\mathrm{e} \\
& \mathrm{H}^{*}+\mathrm{e}(3.4 \mathrm{ev}) \rightarrow \mathrm{H}^{+}+\mathrm{e}+\mathrm{e}
\end{aligned}
$$

An increase in the concentration of the $\mathrm{H}$ and subsequently $\mathrm{H}^{*}$ atoms lead to increase in the secondary ionization processes and hence will lead to an increase in the discharge current which will lead to the transformation of the glow mode to spark mode discharge.

2) Also the gas temperature will be elevated and therefore the density of the gas in the discharge volume will decrease and this will in turn increase the reduced electric field $(\mathrm{E} / \mathrm{N})$ in the gas and consequently share in increasing the spark discharge current enhancement.

Also the fast increase in the current of spark discharge mode to hundreds of milliamperes in nanoseconds can lead to:

1) Back electromotive force can be generated where its magnitude is proportional to the ratio- $d I / d t$.

2) The gas temperature elevation will in turn increases the reduced electric field $(E / N)$ in the gas and consequently enhance the spark discharge current.

3) High density sheathes of charged particles are generated in the discharge volume.

Accordingly, due to the above factors a sharp drop in the discharge voltage will take place (see Figure 4) As the voltage is dropped, the discharge current cannot be sustained anymore and hence the discharge is collapsed and consequently a sudden drop in the discharge current can be noticed in Figure 4. Following the discharge collapses, the sheathes disappear due to the deionization processes then the voltage recovers again to its applied value and hence new cycles of the discharge process are repeated. This mechanism of the discharge gives the discharge its repetitive pulsed behaviour which is shown in Figure 4.

As can be seen in Figure 4, the voltage not only drops to its applied value but also decreases more till it reaches negative values. This behaviour is not only because of the formed sheathes but also because of the back electromotive force generated in the circuit. While the spark discharge is formed, the current increases at a very high rate $(d I / d t)$ which is about $2 \times 10^{7} \mathrm{~A} / \mathrm{s}$. This very high rate of $d I / d t$ forms a back electromotive force which causes the reverse negative voltage in the discharge circuit.

Figure 5 shows the average estimated repetition frequency $f$ as a function of the applied voltage at gas pressure of 5 torr and gap distance of $3 \mathrm{~mm}$. It can be seen that, as the discharge voltage increases the repetition frequency increases. This can be attributed to the increase in the reduced electric field which in turn accelerates the ionization processes and hence reduces the time required for one complete discharge cycle to take place. The results in Figure 4, indicate that the repetition frequency of the discharge can be controlled in the range (0.1 - 2 $\mathrm{MHz})$ using applied voltage in the range of $(0.6-2 \mathrm{kV})$. The repetition frequency can be controlled also by gas pressure. At applied voltage of $0.6 \mathrm{kV}$, the repetition frequency has been decreased from $100 \mathrm{kHz}$ to $5 \mathrm{kHz}$, as the gas pressure increases from 5 torr to 25 torr. In the present work conditions the repetition frequency can be controlled in a wide range from $5 \mathrm{kHz}$ up to $5 \mathrm{MHz}$.

\subsection{Spectroscopic Characteristics}

Figures 6-9 show light spectra emitted from LPG discharge near the cathode and near the anode surfaces (electrodes were made of Brass and Nickel). Various lines and bands can be recognized in these figures. 


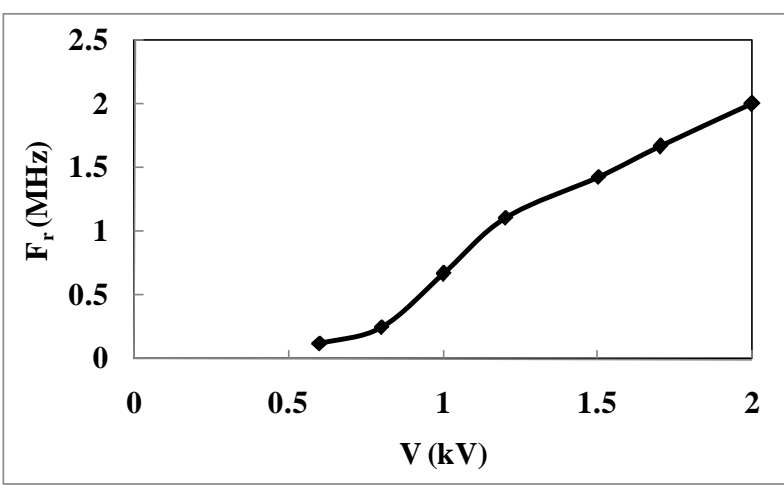

Figure 5. The repetition frequency of the discharge as a function of the applied voltage.

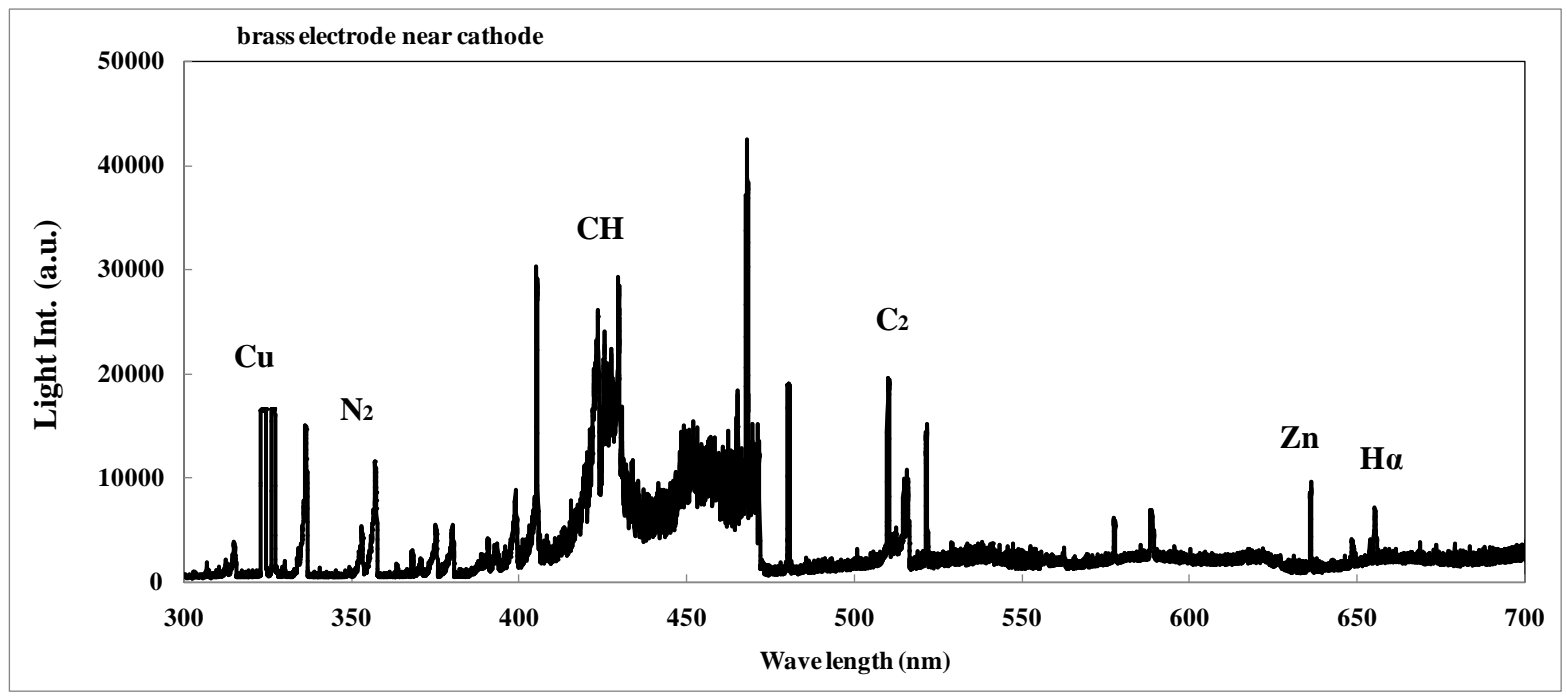

Figure 6. Light spectrum emitted from LPG discharge near the cathode using brass electrodes.

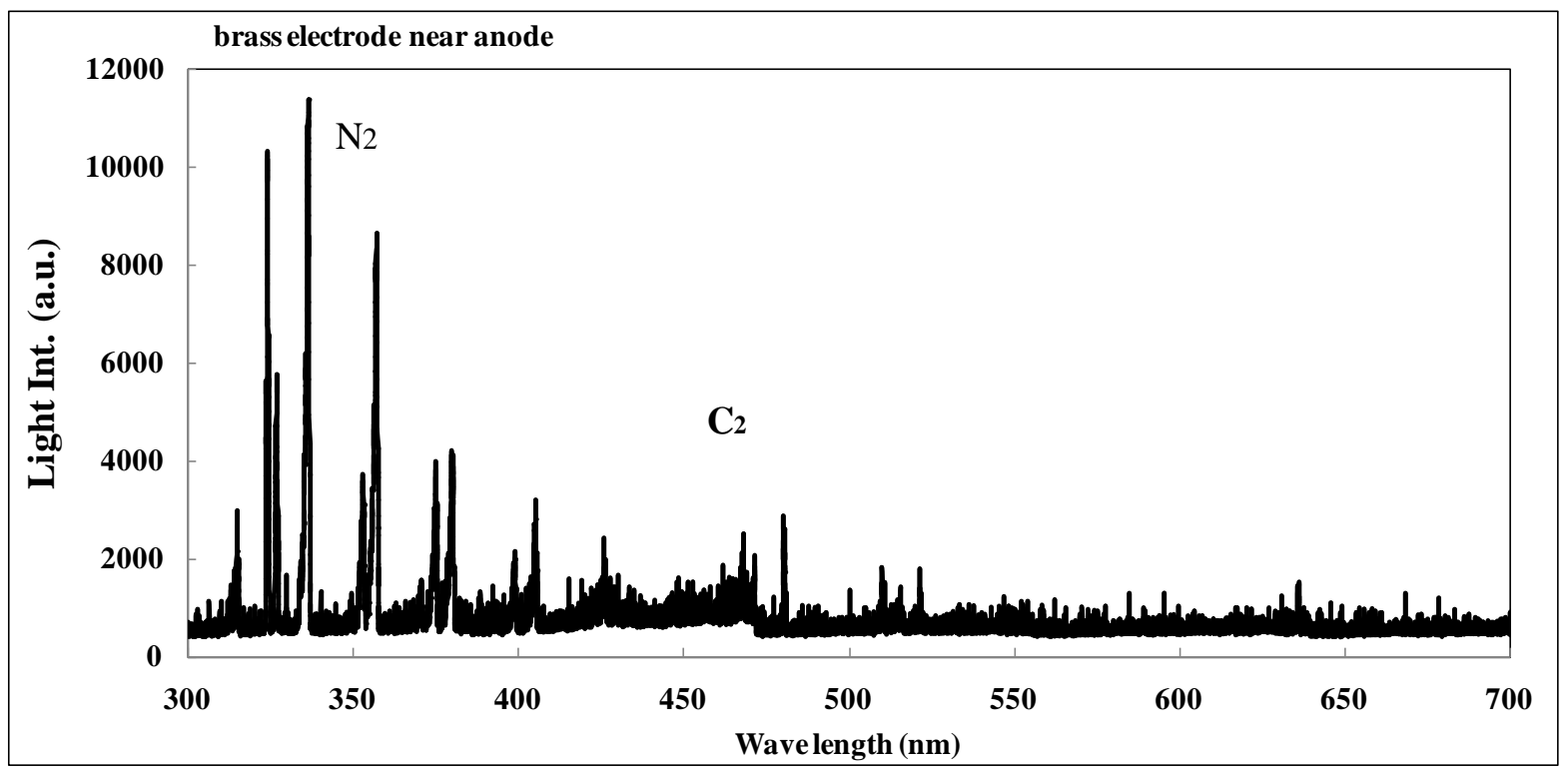

Figure 7. Light spectrum emitted from LPG discharge near the anode using brass electrodes. 


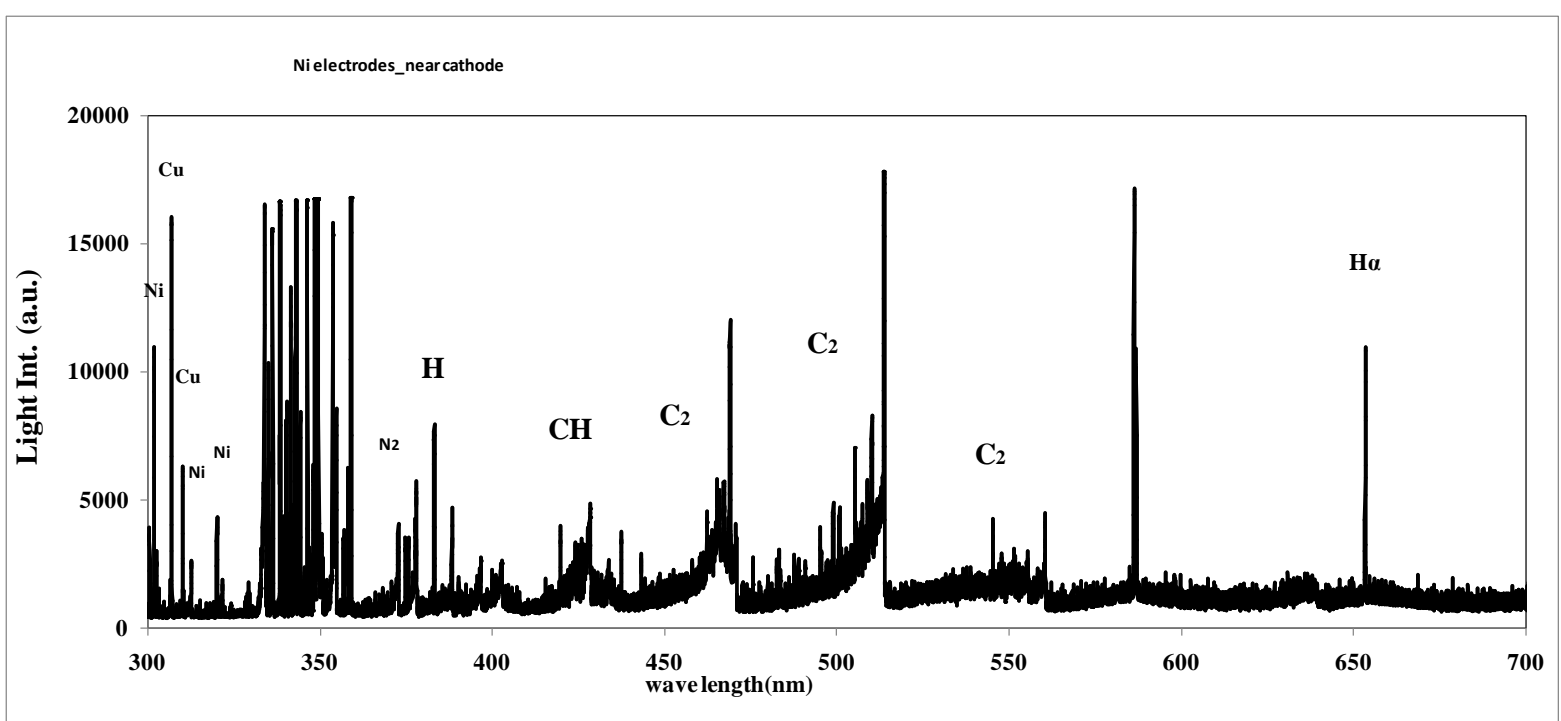

Figure 8. Light spectrum emitted from LPG discharge near the cathode using Ni electrodes.

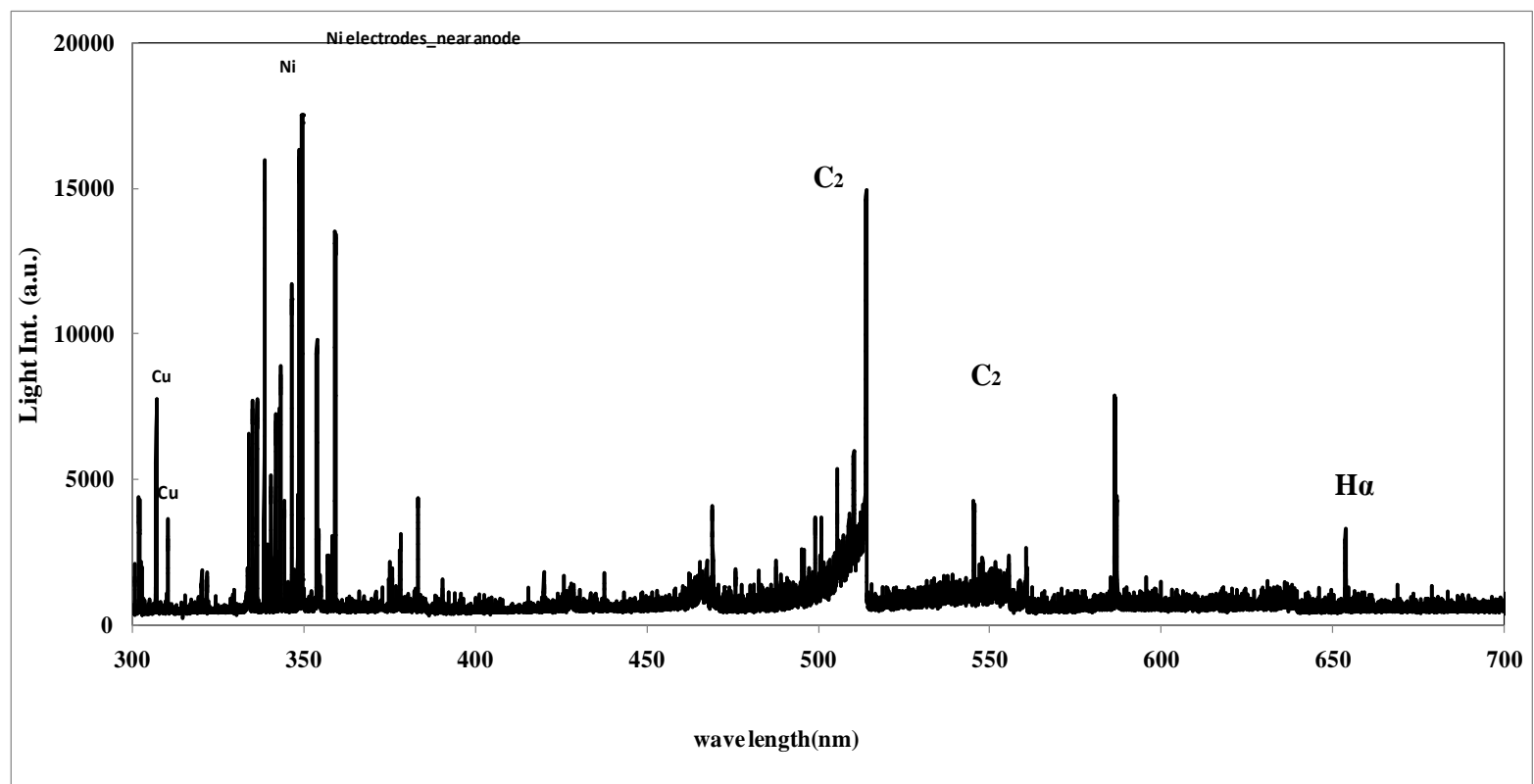

Figure 9. Light spectrum emitted from LPG discharge near the anode using Ni electrodes.

The most recognized spectra in Figure 6 are $\mathrm{C}_{2}, \mathrm{CH}, \mathrm{N}_{2}$ bands, $\mathrm{H}_{\alpha}, \mathrm{Cu}$ and $\mathrm{Zn}$ lines. The appearance of the emitted $H_{\alpha}$ line indicates the existence of hydrogen gas which is formed as natural subsequent of the dissociation of the hydrocarbon components in the above described discharge. The dissociative reactions will be discussed latter in section 3.4. $\mathrm{Cu}$ and $\mathrm{Zn}$ lines indicate the existence of the $\mathrm{Cu}$ and $\mathrm{Zn}$ atoms which are emitted from the brass electrode surface through the evaporation and sputtering processes. Emitted $\mathrm{C}_{2}$ and $\mathrm{CH}$ bands are related to the existence of the $\mathrm{C}_{2}$ molecule and $\mathrm{CH}$ radical which are formed as a result of the dissociation of propane and butane molecules. $\mathrm{N}_{2}$ band confirms the existence of nitrogen molecules due to the existence of some $\mathrm{N}_{2}$ impurities in the discharge tube and in the LPG gas cylinder.

Figure 7 shows the emitted light spectra from the LPG discharge near the anode, using brass electrodes. The most observed spectra near the cathode have been disappeared near the anode, except the $\mathrm{N}_{2}$ band while $\mathrm{C}_{2}$ bands are hardly detected. This difference between the two measured spectra can be explained as follows:

The main source of hydrogen atom $\left(\mathrm{H}_{\alpha}\right.$ line), $\mathrm{C}_{2}$ molecule $\left(\mathrm{C}_{2}\right.$ band) and $\mathrm{CH}$ radical $(\mathrm{CH}$ band) are the dis- 
sociation of propane and butane molecules. The data confirm that the dissociation processes occurs mainly near the cathode. The mean energy of the electrons in the discharge is much higher near the cathode rather than near the anode [8]. Also the spark discharge spots, formed on the cathode, elevate the propane and butane molecules temperature, which in turn enhances the thermal dissociation processes of propane and butane molecules. The resultant species (atoms, molecules and radicals) from the dissociation processes diffuse in all directions and hence their densities near the anode are too low to be detected in the measured spectrum.

Two types of the resultant species are expected; the first one is the unstable species such as hydrogen atoms and $\mathrm{CH}$ radicals, where both of them may react with other species to form more stable species such as hydrogen molecules $\mathrm{H}_{2}$ and hydrocarbon molecules.

The second one is a stable species like $\mathrm{C}_{2}$ molecules which may recombine together to form carbon clusters. The formed carbon clusters diffuse in all directions and then deposits on the electrodes and on the walls of the discharge tube. The deposition of carbon on the electrodes will be discussed later in section 3.3.

Figure 8 shows the emitted light spectra from LPG discharge near the nickel cathode surface where $H_{\alpha}, \mathrm{Cu}$ and Ni lines are recognized. The Ni electrodes have been obtained by coating the brass electrodes with nickel. The intensity of $H_{\alpha}$ line using $\mathrm{Ni}$ cathode electrode is higher than that in the case of brass electrode. This can be related to the fact that $\mathrm{Ni}$ is working as good catalyst for the dissociation of the propane and butane molecules [16] [17]. Existence of $\mathrm{Ni}$ electrode and $\mathrm{Ni}$ atoms in the dissociation zone enhance the rate of dissociation process and hence increases the density of hydrogen atoms. $\mathrm{Cu}$ and $\mathrm{Ni}$ lines indicate the existence of $\mathrm{Cu}$ and $\mathrm{Ni}$ atoms which are emitted from cathode electrode as a result of the evaporation and sputtering processes. $\mathrm{C}_{2}, \mathrm{CH}$ and $\mathrm{N}_{2}$ bands are also recognized in Figure 8 where their intensities are higher than that in the case of brass cathode electrode as a resultant of the effect of the $\mathrm{Ni}$ as a catalyst for the dissociation process. Figure 9 shows the light spectrum emitted from LPG discharge near the anode using Ni electrodes. The $H_{\alpha}$ line and $\mathrm{C}_{2}$ band near the anode have low intensity than near cathode. These spectra did not noticed for the brass anode. The appearance of $H_{\alpha}$ line and $\mathrm{C}_{2}$ band near the anode can be attributed to the higher density of hydrogen and carbon molecules which are produced near the cathode region and hence diffuse to the anode. The intensity of the $H_{\alpha}$ line can be taken as an indicator to the density of the hydrogen atoms and hence to the high rate of the dissociation process. The intensity of the $H_{\alpha}$ line $\left(I_{H \alpha}\right)$ can be expressed in the form [18]:

$$
I_{H \alpha}=N_{e} N_{H}\left\langle Q_{H \alpha}\left(v_{e}\right) v_{e}\right\rangle
$$

where $N_{e}$ is the electron density, $N_{H}$ is the hydrogen atoms density, $Q_{H \alpha}$ is the cross section of the excitation process of hydrogen atoms, $v_{e}$ is the electron velocity and the symbol $<>$ indicates to the average of the product over a Maxwellian velocity distribution. Figure 10 shows the relative intensity of $H_{\alpha}$ line as a function of the applied voltage. It cab seen that, the intensity of $H_{\alpha}$ line increases as the applied voltage increases, which can be attributed to the increase in the electron density $N_{e}$, the mean electron energy and hydrogen atom density $N_{H}$.

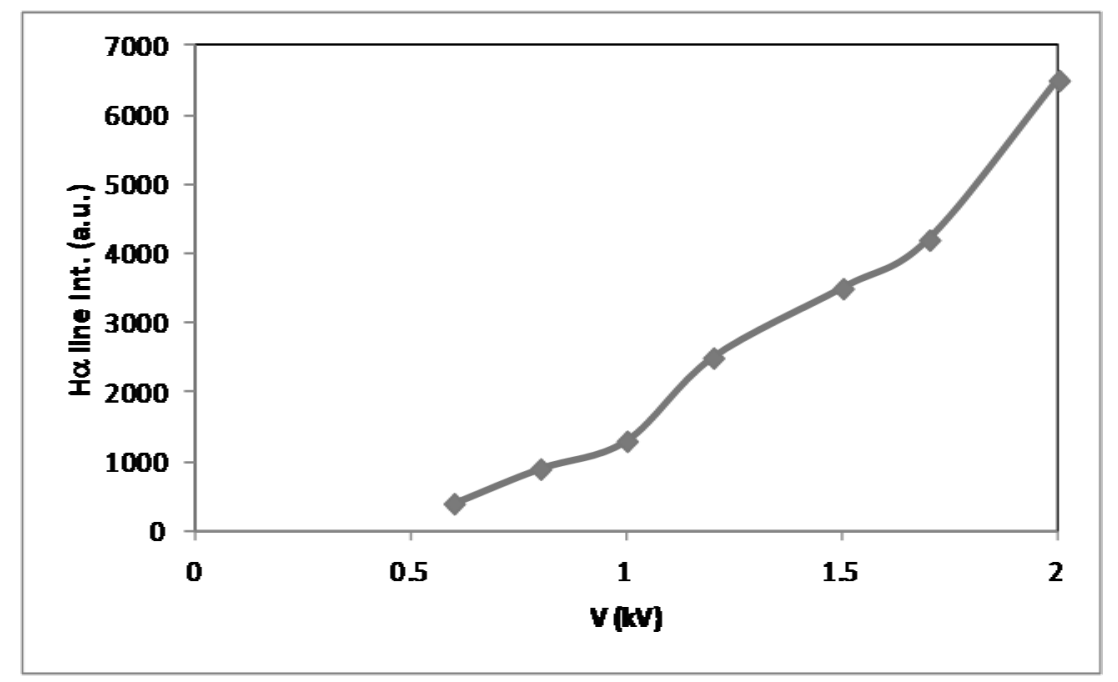

Figure 10. Relative intensity of the emitted $H_{\alpha}$ line as a function of the applied voltage. 


\section{Conclusion}

The electric and spectroscopic characteristics of electric discharge have been used to explore the discharge mechanisms in LPG. A deviation from Paschen's law has been reported which has been attributed to the diffusion outside the discharge volume of the active species of secondary processes such as photons and excited atoms. The discharge has a repetitive behaviour where each cycle consists of three phases; discharge off, glow discharge and spark discharge. The repetition frequency of the discharge covers a wide range from $5 \mathrm{kHz}$ to $5 \mathrm{MHz}$ which depends on the applied voltage and the gas pressure. It is concluded that the present discharge modes are very useful for the dissociation of LPG molecules. Hydrogen atoms, $\mathrm{C}_{2}$ molecule and $\mathrm{CH}$ radical have been detected in the discharge spectra using emission spectroscopy measurements. The dissociation processes are attributed to two processes; the electron collision with propane and butane molecules during the glow discharge mode and the gas heating due to the spark discharge mode. The dissociation process occurs mainly near the cathode surface wherein the electron density and the gas temperature are the highest. Besides working as a cathode, Ni electrode has been proven to be a good catalyst for increasing the dissociation rate of propane and butane molecules.

\section{Acknowledgements}

This work has been supported by the Science and Technology Development Fund (STDF), Egypt. Project ID: 3897.

\section{References}

[1] Qi, D.H., Bian, Y.ZH., Ma, ZH.Y., Xhang, CH.H. and Liu, SH.Q. (2007) Energy Conversion and Management, 48, 500-509. http://dx.doi.org/10.1016/j.enconman.2006.06.013

[2] Zhang, C.H., Bian, Y.Z., Si, L.Z., Liao, J.Z. and Odbileg, N. (2005) Proceedings of the Institution of Mechanical Engineers, Part D: Journal of Automobile Engineering, 219, 207-213. http://dx.doi.org/10.1243/095440705X6470

[3] Capezzuto, P., Cramarossa, F., D’agostino, R. and Molinari, E. (1977) The Decomposition of Methane, Ethane, Ethylene and n-Butane in Electrical Discharges of Moderate Pressures. Contributions to Plasma Physics, 17, 205-220.

[4] Lindner, P.J. and Besser, R.S. (2012) International Journal of Hydrogen Energy, 37, 13338-13349. http://dx.doi.org/10.1016/j.ijhydene.2012.06.054

[5] Moshrefi, M.M., Rashidi, F., Bozorgzadeh, H.R. and Zekordi, S.M. (2012) Plasma Chem Plasma Process, 32, 11571168. http://dx.doi.org/10.1007/s11090-012-9408-6

[6] Smyaglikov, I.P., Chekan, N.M., Akula, I.P., Pobol, I.L. and Rajczyk, J. (2013) Vacuum, 90, 165-169. http://dx.doi.org/10.1016/j.vacuum.2012.03.044

[7] Auday, G., Guillot, Ph. and Galy, J. (2000) Journal of Applied Physics, 88, 4871-4874. http://dx.doi.org/10.1063/1.1290461

[8] Garamoon, A.A., Samir, A., Elakshar, F.F. and Kotp, E.F. (2003) Plasma Sources Science and Technology, 12, 417420. http://dx.doi.org/10.1088/0963-0252/12/3/317

[9] Lisovskiy, V.A., Yakoven, S.D. and Yegorenkov, V.D. (2000) Journal of Physics D: Applied Physics, 33, $2722-2730$. http://dx.doi.org/10.1088/0022-3727/33/21/310

[10] El-Zeer, D.M., Samir, A., Elakshar, F.F. and Garamoon, A.A. (2013) Journal of Modern Physics, 4, 160-167. http://dx.doi.org/10.4236/jmp.2013.42022

[11] Von Engel, A. (1983) Electric Plasma the Nature and Uses. Tayler and Frances Ltd., London and New York.

[12] Agira, L.A. and Trionfetti, C. (2007) Kinetic Model Analysis of C3H8 Plasma for Olefin Synthesis in Microplasma Reactors. 28th ICPIG, Prague, 15 July 2007, 260.

[13] Young, N.C. (2006) Journal of Industrial and Engineering Chemistry, 12, 552-557.

[14] Muradov, N. (2000) Thermocatalytic $\mathrm{CO}_{2}$-Free Production of Hydrogen from Hydrocarbon Fuels. Proceedings of the 2000 Hydrogen Program Review, NREL/CP-570-28890.

[15] Malaibari, Z. (2011) Hydrogen Production from Liquefied Petroleum Gas (LPG) by Oxidative Steam Reforming Over Bimetallic Catalysts. Doctor of Philosophy in Chemical Engineering, University of Waterloo, Waterloo.

[16] Hammer, Th., Kappes, Th. and Baldauf, M. (2004) Catalysis Today, 89, 5-14. http://dx.doi.org/10.1016/j.cattod.2003.11.001

[17] Nozaki, T., Muto, N., Kado, S. and Okazaki, K. (2004) Catalysis Today, 89, 57-65. http://dx.doi.org/10.1016/j.cattod.2003.11.040

[18] Griem, H.R. (1964) Plasma Spectroscopy. McGraw-Hill, New York. 
Scientific Research Publishing (SCIRP) is one of the largest Open Access journal publishers. It is currently publishing more than 200 open access, online, peer-reviewed journals covering a wide range of academic disciplines. SCIRP serves the worldwide academic communities and contributes to the progress and application of science with its publication.

Other selected journals from SCIRP are listed as below. Submit your manuscript to us via either submit@scirp.org or Online Submission Portal.
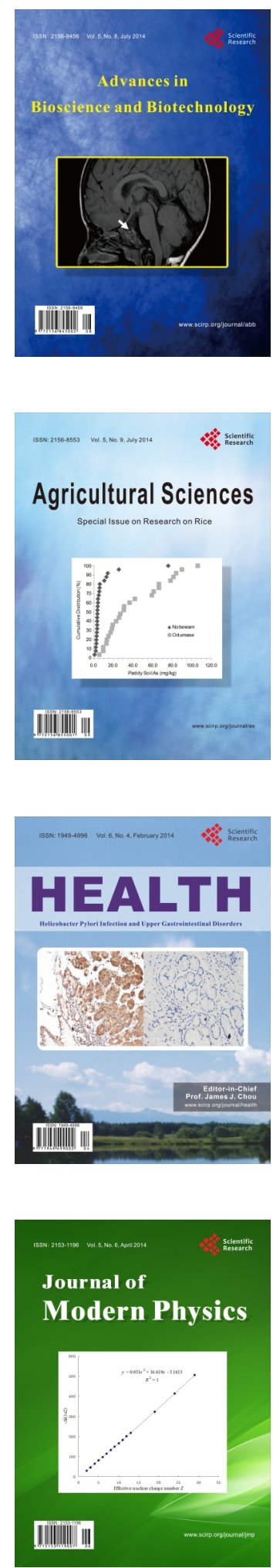
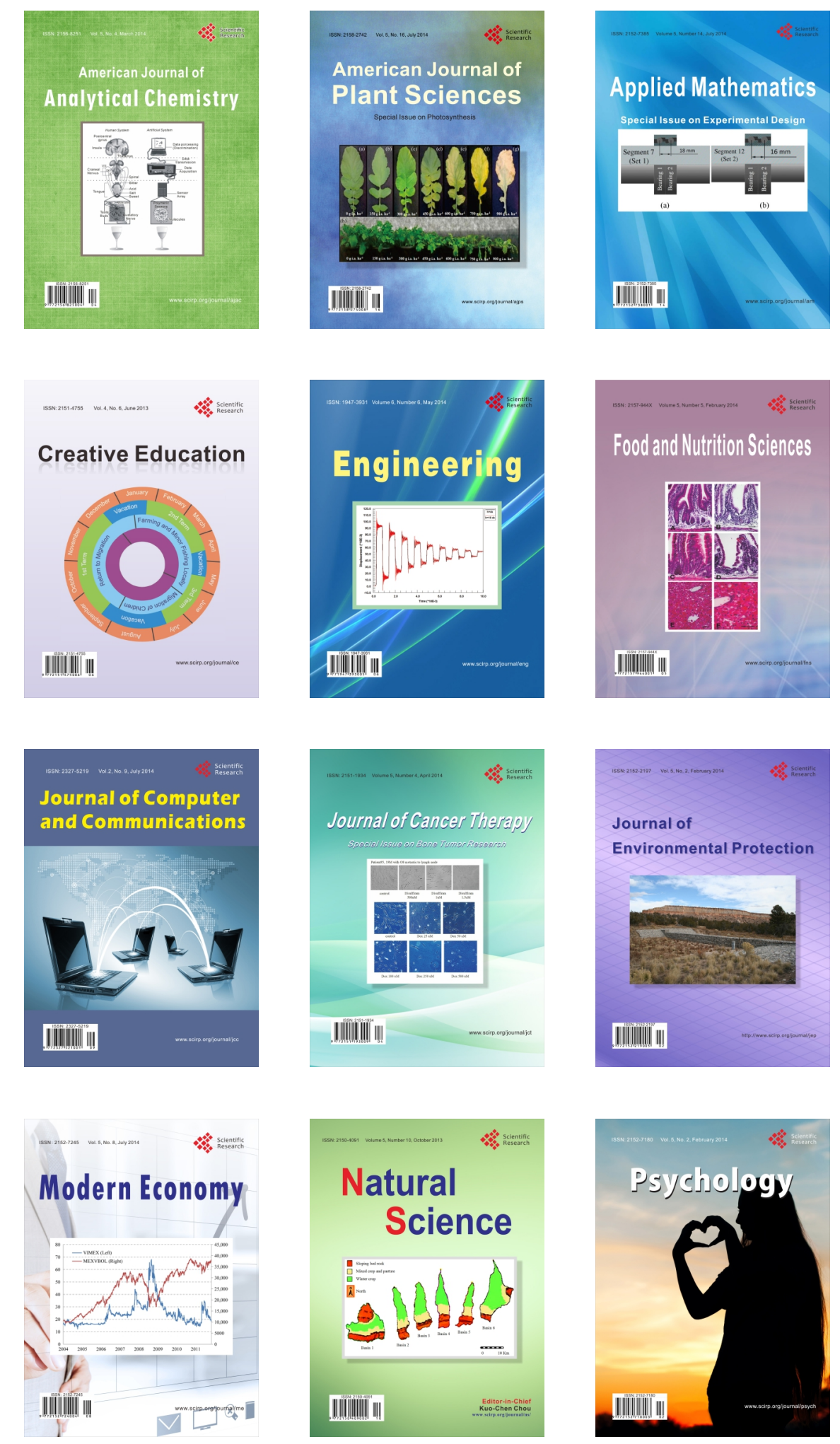